\title{
Faktor-Faktor yang Mempengaruhi Kepuasan Konsumen Kedai "Pesenkopi" di Kota Malang
}

Siti Saniah ${ }^{1}$, Bambang Yudi Ariadi $2^{\star}$, Harpowo ${ }^{3}$

Program Studi Agribisnis Fakultas Pertanian dan Peternakan Universitas Muhammadiyah Malang, Jalan Raya Tlogomas No. 246 Malang, Jawa Timur, Indonesia.

${ }^{1}$ Ssaniahgot7@gmail.com ; ${ }^{2}$ bambang y@umm.ac.id ; 3 Harpowo@gmail.com

* corresponding author

\begin{tabular}{|c|c|}
\hline ARTICLE INFO & ABSTRACT \\
\hline $\begin{array}{l}\text { Article history } \\
\text { Received August 08, } 2020 \\
\text { Revised August 18, } 2020 \\
\text { Accepted August 26, } 2020 \\
\text { Published August 27, } 2020 \\
\text { Keywords } \\
\text { Brand } \\
\text { Coffee shop } \\
\text { Consumer's loyalty } \\
\text { Costumer's satisfaction } \\
\text { Product quality }\end{array}$ & $\begin{array}{l}\text { The study purposed to analyze the influence of the product's quality, brand, and } \\
\text { consumer's loyalty on the consumer's satisfaction at the Coffee Shop of "Pesenkopi". } \\
\text { The research was conducted at the "Pesenkopi" Coffe Shop on November-December } \\
2019 \text {, in Kota Malang, East Java. The primary data were obtained from the consumers } \\
\text { of "Pesenkopi" by using questionnaire. The accidental sampling took } 75 \text { respondents } \\
\text { who answered the questionnaire. The data obtained were analyzed with the Structural } \\
\text { Equation Model, done by the WarpPLS. The result showed that Consumer loyalty has a } \\
\text { very significant effect on their satisfaction, while product and brand quality have no } \\
\text { significant effect. The most important indicator of loyalty was recommending products to } \\
\text { others, while on the product quality was the distinctive aroma of the coffee at } \\
\text { "Pesenkopi", and on the brand was packaging. The practical recommendations given } \\
\text { were that the distinctive coffee aroma of "Pesenkopi" has to be maintained and } \\
\text { accompanied by a good service, so that the brand image owned encourages } \\
\text { consumers to recommend the products to the other consumers. The suggestions for the } \\
\text { future research are analyzing the purchasing intensity and the characteristics of } \\
\text { adolescent consumers in more detail for segmenting the market. } \\
\text { This is an open access article under the CC-BY-SA license }\end{array}$ \\
\hline
\end{tabular}

\section{PENDAHULUAN}

Perkembangan jaman dan teknologi saat ini semakin pesat, sehingga konsep pemasaran juga mengalami perkembangan. Bidang kuliner sudah mulai menjadi trend di kalangan masyarakat Indonesia terutama kuliner di bidang minuman seperti kopi. Usaha bisnis kedai kopi mengalami pertumbuhan dari usaha kecil, menengah hingga perusahaan besar. Gaya hidup masyarakat kota menjadi semakin bervariasi, salah satunya adalah gaya hidup konsumtif. 'Ngopi' merupakan istilah saat orang sedang santai dan menikmati kopi bersama kerabat atau teman-teman, sehingga bisnis kedai kopi juga makin banyak tumbuh dan berkembang.

Persaingan bisnis kedai kopi semakin ketat dalam rangka mendapatkan perhatian dan loyalitas konsumen. Banyak kedai kopi yang berlomba untuk memberikan kualitas yang baik, merek yang mudah dikenal dan loyalitas konsumen. Setiap bisnis harus mampu bersaing dengan bisnis yang sejenis, untuk bertahan dan memenangkan persaingan saat ini. Banyak cara yang dilakukan bisnis, untuk meningkatkan kepuasan konsumen. Faktor yang harus diperhatikan yaitu kualitas produk, merek dan loyalitas konsumen. 
Kualitas produk merupakan totalitas dan karakteristik untuk memuaskan kebutuhan, kualitas produk merupakan ketahanan suatu produk, kehandalan, ketepatan, kemudahan operasi dan perbaikan, serta atributatribut nilai lainnya (Kotler \& Keller, 2006). Dari sudut pandang pemasaran, kualitas harus diukur sehubungan dengan persepsi kualitas para pembeli (Hermawan, 2011). Usaha bisnis yang mampu memberikan kualitas produk yang tinggi akan lebih memberi keuntungan dibandingkan dengan kualitas produk rendah. Konsumen akan bersedia membeli asalkan kualitas produk baik. Kualitas produk merupakan salah satu pertimbangan yang penting bagi konsumen untuk membeli produk. Kualitas produk yang baik memenuhi kebutuhan dan keinginan konsumen terhadap suatu produk.

Merek juga penting untuk keberhasilan dan kemajuan usaha bisnis. Bisnis yang sudah memiliki nama khas (merek) memberi keuntungan lebih untuk diketahui dan dikenal banyak konsumen. Menurut Kotler \& Keller (2012) merek merupakan keyakinan konsumen terhadap suatu produk yang sudah tertanam di benak konsumen, atau persepsi konsumen terhadap suatu produk dengan keyakinan yang positif. Citra merek yang positif sangat penting bagi perusahaan untuk mempertahankan keberadaan suatu bisnis. Citra merek dapat memberikan kesan yang baik terhadap kualitas suatu produk atau jasa. Konsumen seringkali memilih produk yang memiliki citra merek yang positif (Fatlahah, 2013).

Loyalitas konsumen merupakan ukuran keterkaitan konsumen terhadap suatu merek. Ukuran ini mampu memberikan gambaran tentang terjadinya konsumen berpindah ke produk lain. Faktor yang mempengaruhi loyalitas konsumen misalnya kualitas produk dan merek yang mengarah pada kepuasan konsumen. Loyalitas konsumen dapat dipengaruhi oleh kualitas produk dan merek. Loyalitas konsumen menunjukkan bahwa konsumen akan menjadi loyal pada beberapa merek yang berkualitas tinggi. Loyalitas pelanggan lebih banyak dikaitkan dengan perilaku daripada sikap. Perilaku adalah ketika pelanggan melakukan pembelian, sedangkan sikap adalah perasaan yang ditunjukkan oleh pelanggan setelah menggunakan produk. Pelanggan yang loyal, akan menunjukkan perilaku pembelian yang dilakukan dari waktu ke waktu (Saraswati, 2014).

Kepuasan konsumen merupakan konsep penting dalam pemasaran. Kepuasan telah menjadi subjek penelitian konsumen yang dilakukan banyak usaha bisnis untuk mengetahui apakah keinginan dari konsumen. Usaha bisnis melihat pentingnya kepuasan konsumen dengan memberikan kualitas produk yang baik, merek yang sudah dikenal, serta loyalitas konsumen dalam membeli suatu produk. Tujuannya adalah memberikan keuntungan yang lebih pada konsumen. Kepuasan didefinisikan sebagai tingkat perasaan seseorang setelah membandingkan kinerja atau hasil yang dirasakan dengan harapannya. Tingkat kepuasan merupakan fungsi dari perbedaan antara kinerja yang dirasakan dengan harapan. Apabila kinerja dibawah harapan, maka pelanggan akan sangat kecewa; bila kinerja sesuai atau melebihi harapan, maka pelanggan akan sangat puas (Hayati \& Hakim, 2014).

Kedai "Pesenkopi" merupakan salah satu bisnis kedai kopi yang tengah berkembang di Jawa Timur. Bisnis kedai kopi merek ini sudah berkembang di beberapa kota (Malang, Jember, Surabaya, Sidoarjo, dan Bali). Kedai "Pesenkopi" berdiri pada 8 Agustus 2018, yang paling berkembang saat ini adalah yang berada di Kota Malang. "Pesenkopi" Malang sudah memiliki kurang lebih 20 cabang. Inovasi kreatif dan inovatif Kedai "Pesenkopi" memiliki beberapa varian menu dan terus berkembang untuk memenuhi kebutuhan dan selera konsumen. Menu yang disediakan di Kedai "Pesenkopi" Malang terdiri dari coffee, flavor, tea dan cokelat serta dilengkapi dengan beberapa kue yang disediakan. Pemasaran di "Pesenkopi" sangat unik, misalnya saat opening cabang kedai "Pesenkopi" mereka membagikan 1000 cup es kopi susu gratis kepada setiap pembelinya, dan harganya terjangkau berkisar Rp10.000/cup.

Kedai "Pesenkopi" merupakan salah satu kedai kopi yang menggunakan sistem take away, dan hanya ada beberapa fasilitas tempat duduk untuk menunggu pelayanan kopi. Bangunan kedai tidak luas, lebih mirip post satpam (sekitar $2 \times 2 \mathrm{~m}^{2}$ ), dan area parkirnya juga sempit. Tetapi kedai "Pesenkopi" saat ini diburu konsumen penikmat kopi. Pesaing kedai "Pesenkopi" sudah sangat banyak, mereka meniru sistem pemasaran. Agar kedai dapat bertahan dalam persaingan, Kedai "Pesenkopi" saat ini harus bisa memenuhi keinginan dan kebutuhan konsumen melalui kualitas produk, merek, loyalitas dan kepuasan konsumen. Selain itu Kedai "Pesenkopi" harus bisa memberikan sesuatu yang berbeda bagi konsumen agar mereka tidak cepat merasa bosan dan berpindah ke kedai kopi lain.

Beberapa hasil penelitian pada kedai kopi menemukan pengaruh produk, merek, dan pelayanan terhadap loyalitas dan kepuasan konsumen. Merek, perusahaan pembuat merek, dan konsumen mempengaruhi loyalitas merek (Kurniawan, 2011; Iriani, 2013: Saraswati, 2014; Gedalia, 2015). Kualitas produk minuman kopi terutama dalam aspek aesthetics berpengaruh lebih besar terhadap kepuasan konsumen (Liany, 2016). Kualitas pelayanan kedai kopi mempengaruhi kepuasan kosumen, dan kepuasan konsumen berimplikasi terhadap terbentuknya loyalitas konsumen (Marliana, 2017). Citra merek meliputi kekuatan asosiasi merek, 
keuntungan asosiasi merek dan keunikan asosiasi merek secara parsial berpengaruh loyalitas konsumen kedai kopi di Surabaya (Wijayanto \& Iriani, 2013). Hasil yang berbeda pada penelitian tentang kedai kopi adalah kualitas produk tidak berpengaruh terhadap kepuasan pelanggan; namun kualitas layanan berpengaruh terhadap kepuasan pelanggan, kualitas produk dan kualitas layanan juga tidak berpengaruh terhadap loyalitas pelanggan; kepuasan pelanggan berpengaruh terhadap loyalitas pelanggan dan berfungsi sebagai mediasi sempurna antara kualitas layanan dan loyalitas pelanggan (Kusumasasti et al., 2017).

Pada produk minuman lainnya (teh, cola) juga terdapat beberapa hasil penelitian yang mengkaji kepuasan konsumen. Ekuitas merek teh yang meliputi perhatian merek dan citra merek berpengaruh terhadap terhadap keputusan pembelian dan kepuasan konsumen (Lukman, 2014). Kepercayaan, nilai pelanggan, citra perusahaan, berpengaruh terhadap kepuasan konsumen minuman cola, namun variabel-variabel tersebut tidak berpengaruh terhadap loyalitas merek, dan kepuasan konsumen berpengaruh terhadap loyalitas merek (Lintong, 2014). Kualitas layanan, brand image dan atmosfir yang dimiliki oleh kedai Deja-Vu Surabaya juga berpengaruh terhadap kepuasan konsumen, selanjutnya kepuasan konsumen berpengaruh terhadap loyalitas konsumen (Harianto \& Subagio, 2013).

Berbagai penelitian pada kedai kopi mengambil merek yang sudah ternama, seperti Starbucks. Kebaruan penelitian pada Kedai "Pesenkopi" adalah analisis loyalitas dan kepuasan konsumen pada kedai kopi yang belum mempunyai brand ternama, dan sistem pembelian dilakukan dengan take away. Tujuan penelitian adalah untuk mengetahui pengaruh kualitas produk, merek, dan loyalitas konsumen terhadap kepuasan konsumen Kedai "Pesenkopi" di Kota Malang. Hipotesis yang dirumuskan adalah: 1) Kualitas produk mempengaruhi kepuasan konsumen; 2) Merek produk mempengaruhi kepuasan konsumen; 3) Loyalitas konsumen mempengaruhi kepuasan konsumen. Penelitian ini diharapkan memberikan kontribusi praktis dan teoritis tentang konsep pemasaran kopi sistem take away.

\section{METODE PENELITIAN}

Data primer diperoleh dengan cara membagikan kueisioner pada konsumen di Kedai "Pesenkopi" Kota Malang. Data kuantitatif berupa angka yang dapat dihitung seperti jumlah konsumen di Kedai "Pesenkopi" Malang. Pengumpulan data primer dilakukan pada bulan November-Desember 2019. Pengambilan sampel konsumen dilakukan dengan accidental sampling, yaitu teknik pengumpulan sampel secara kebetulan yakni konsumen yang saat pengumpulan data tengah melakukan pembelian di Kedai "Pesenkopi". Sampel penelitian sejumlah 75 responden. Kueisioner diisi oleh responden yang telah mengkonsumsi Kedai "Pesenkopi" Malang minimal dua kali pembelian. Skala Likert digunakan untuk mengukur tanggapan responden terhadap setiap pertanyaan yang dikemukakan.

Data dianalisis dengan Structural Equation Modelling (SEM).dengan piranti WarpPLS. Berbagai uji dilakukan untuk ketepatan model SEM, meliputi model fit, reliabilitas, validitas, dan Adjusted R-squared coefficients. Uji hipotesis digunakan path coefficients dan P-value. Tabel 1 menunjukkan hasil uji model fit and quality indices. Uji ini digunakan untuk mengetahui adanya kesesuaian model penelitian. Hubungan model yang baik menggambarkan kesesuaian hubungan anatara variabel dalam penelitian.

Tabel 1. Uji model penelitian (model fit and quality indices)

\begin{tabular}{lcc}
\hline \multicolumn{1}{c}{ Keterangan } & Nilai & Ideal \\
\hline Average path coefficient (APC) & $0,312(P<0.001)$ & $<=0,05$ \\
Average adjusted R-squared (AARS) & $0,719(P<0.001)$ & $<=0,05$ \\
Average block VIF (AVIF) & 1,792 & $<=5 /<=3,3$ \\
\hline
\end{tabular}

Sumber: Data primer diolah, 2020

Tabel 1 menunjukkan bahwa masing-masing nilai pada APC, AARS, dan AVIF dalam model SEM telah memenuhi kriteria kesesuaian model. Hasil analisis tersebut menunjukkan bahwa APC mempunyai nilai $P$ value $<0,001$ yang memenuhi kriteria ideal $<0,05$. Nilai AARS mempunyai nilai $P$ value $<0,001$ juga memenuhi ideal $<0,05$. Nilai AVIF sebesar 1,792 lebih kecil dari 3,3 maka memenuhi kriteria ideal.

\section{2}

Saniah et.al (Faktor-faktor yang mempengaruhi kepuasan konsumen kedai "Pesenkopi" di Kota Malang, Brand coffe shop, Consumer loyalti, Costumer's satisfaction, Product quality) 


\section{HASIL DAN PEMBAHASAN}

\section{Karakteristik Responden}

Konsumen kedai "Pesenkopi" Malang menurut mayoritas adalah perempuan, yakni sebanyak 52 responden $(69,4 \%)$, sedangkan konsumen laki-laki hanya 23 responden $(30,6 \%)$. Mayoritas konsumen adalah usia remaja, kisaran umur responden adalah 19 hingga 24 tahun.

Mayoritas konsumen kedai "Pesenkopi" Malang adalah pelajar atau mahasiswa. Kedai "Pesenkopi" ini terletak di beberapa kawasan kampus di Kota Malang, jadi jumlah konsumen dari pelajar atau mahasiswa sebanyak 70 responden dengan presentase $93,3 \%$. Persentase sisanya adalah Pegawai Negeri Sipil dan karyawan swasta.

Jumlah pendapatan konsumen dalam hal ini lebih tepatnya adalah uang yang diterima dari orang tua untuk biaya hidup selama satu bulan. Perkecualian pada responden PNS dan karyawan swasta, pendapatan adalah gaji atau penerimaan yang mereka peroleh selama satu bulan. Pendapatan perbulan konsumen kedai "Pesenkopi" Malang berkisar Rp 500.000 hingga Rp 3.500 .000 per bulan. Pendapatan konsumen yang mayoritas adalah pada kisaran Rp 500.000 - Rp 1.500.000 dengan persentase $70,6 \%$.

\section{Uji Reliabilitas dan Validitas}

Pengujian reliabilitas bertujuan untuk memastikan bahwa instrumen penelitian yang digunakan menghasilkan pengukuran konsep secara konsisten tanpa ada bias. Tabel 2 menunjukkan nilai Cronbach's berkisar 0,7 hingga lebihd ari 0,9. Variabel laten semakin reliabel jika memiliki Composite Reliablity di atas 0,60 atau mendekati angka 1 (Hayati \& Hakim, 2014). Penjelasan hasil uji ini adalah nilai dari composite reliability coefficients dan Cronbach's alpha coefficients > dari 0,5 maka dinyatakan reliabel. Instrumen penelitian ini memenuhi ketentuan uji reliabilitas.

Tabel 2. Uji Reliabilitas (latent variable coefficients)

\begin{tabular}{lccl}
\hline \multicolumn{1}{c}{ Latent variable } & $\begin{array}{c}\text { Composite reliability } \\
\text { coefficients }\end{array}$ & $\begin{array}{c}\text { Cronbach's alpha } \\
\text { coefficients }\end{array}$ & Keterangan \\
\hline X1 (Kualitas Produk) & 0,817 & 0,716 & Reliabel \\
X2 (Merek) & 0,901 & 0,862 & Reliabel \\
X3 (Loyalitas) & 0,954 & 0,939 & Reliabel \\
Y(Kepuasan konsumen) & 0,947 & 0,916 & Reliabel \\
\hline
\end{tabular}

Sumber: Data primer diolah, 2020

Uji validitas menunjukkan kesesuaian setiap indikator dengan teori yang digunakan untuk mendefinisikan suatu konstruk. Kriteria uji validitas adalah menggunakan kriteria loading $>0,5$; loading > cross-loadings; dan Average Variances Extracted (AVE) > 0,50.

Tabel 3 menunjukkan bahwa semua indikator memiliki nilai loading yang lebih besar dari 0,3 dan lebih besar dari cross loading. Nilai loading $>0,3$ mengindikasikan validitas konvergen, sedangkan nilai loading lebih besar dari cross loading mengindikasikan validitas diskriminan (Hayati \& Hakim, 2014). 
Tabel 3. Hasil pengujian Combined Loading and Cross Loading

\begin{tabular}{lcccc}
\hline \multicolumn{1}{c}{ Variabel } & $\begin{array}{c}\mathbf{X}_{1} \\
\text { Kualitas produk }\end{array}$ & $\begin{array}{c}\mathbf{X}_{2} \\
\text { Merek }\end{array}$ & $\begin{array}{c}\mathbf{X}_{3} \\
\text { Loyalitas }\end{array}$ & $\begin{array}{c}\mathbf{Y} \\
\text { Kepuasan konsumen }\end{array}$ \\
\hline X1.1 Rasa enak & 0,753 & 0,039 & 0,084 & 0,121 \\
X1.2 Varian rasa & 0,553 & 0,344 & $-0,535$ & 0,359 \\
X1.3 Kualitas kopi & 0,779 & $-0,008$ & 0,089 & $-0,172$ \\
X1.4 Aroma kopi & 0,836 & $-0,129$ & 0,149 & $-0,203$ \\
X1.5 Tanpa pengawet & 0,481 & $-0,221$ & 0,080 & 0,028 \\
X2.1 Reputasi merek & 0,137 & 0,786 & 0,002 & $-0,050$ \\
X2.2 Take away & 0,009 & 0,762 & $-0,299$ & 0,415 \\
X2.3 Mudah diingat & 0,177 & 0,748 & $-0,710$ & 0,438 \\
X2.4 Kemasan & $-0,099$ & 0,885 & 0,425 & $-0,290$ \\
X2.5 Logo & $-0,193$ & 0,831 & 0,459 & $-0,419$ \\
X3.1 Pembelian ulang & $-0,184$ & 0,272 & 0,888 & 0,117 \\
X3.2 Merekomendasi & 0,064 & $-0,053$ & 0,924 & $-0,140$ \\
X3.3 Setia merek & 0,114 & $-0,148$ & 0,921 & $-0,120$ \\
X3.4 Respon promosi & $-0,174$ & 0,038 & 0,849 & 0,087 \\
X3.5 Respon varian rasa & 0,163 & $-0,098$ & 0,904 & 0,069 \\
Y1 Kepuasan kualitas & 0,004 & 0,068 & 0,274 & 0,929 \\
Y2 Kepuasan layanan & 0,063 & $-0,120$ & $-0,168$ & 0,954 \\
Y3 Kepuasan harga & $-0,072$ & 0,058 & $-0,106$ & 0,893 \\
\hline
\end{tabular}

Sumber: Data primer diolah, 2020

Nilai akar kuadrat dari Average variances extracted (AVEs) ditunjukkan dalam diagonal dan dicetak tebal. Tabel 4 menunjukkan informasi nilai akar AVE variabel yang sama lebih tinggi dari pada nilai akar AVE pada variabel berbeda. Hal ini sudah memenuhi kriteria uji validitas. Instrumen yang digunakan dalam penelitian ini telah memenuhi semua uji validitas dan nilai AVE $>0,50 . X 1$ (Kualitas produk) sudah memenuhi uji validitas dengan nilai 0,694 >0,50 dan X2 (Merek) sudah memenuhi uji validitas dengan nilai 0,804 >0,50. X3 (Loyalitas) sudah memenuhi uji validitas dengan nilai 0,898 >0,50 dan $Y$ (Kepuasan konsumen) sudah memenuhi uji validitas dengan nilai 0,926 >0,50.

Tabel 4. Perbandingan akar dari AVE dengan korelasi variabel

\begin{tabular}{ccccc}
\hline & $\begin{array}{c}\mathbf{X}_{1} \\
\text { Kualitas produk }\end{array}$ & $\begin{array}{c}\mathbf{X}_{2} \\
\text { Merek }\end{array}$ & $\begin{array}{c}\mathbf{X}_{3} \\
\text { Loyalitas }\end{array}$ & $\begin{array}{c}\mathbf{Y} \\
\text { Kepuasan }\end{array}$ \\
\hline $\mathbf{X}_{1}$ & $\mathbf{0 , 6 9 4}$ & 0,504 & 0,602 & 0,546 \\
$\mathbf{X}_{2}$ & 0,504 & $\mathbf{0 , 8 0 4}$ & 0,618 & 0,624 \\
$\mathbf{X}_{3}$ & 0,602 & 0,618 & $\mathbf{0 , 8 9 8}$ & 0,835 \\
$\mathbf{Y}$ & 0,546 & 0,624 & 0,835 & $\mathbf{0 , 9 2 6}$ \\
\hline
\end{tabular}

Sumber: Data primer diolah, 2020

Tabel 5. Average variances extracted

\begin{tabular}{cccc}
\hline $\begin{array}{c}\mathbf{X}_{1} \\
\text { Kualitas Produk }\end{array}$ & $\begin{array}{c}\mathbf{X}_{2} \\
\text { Merek }\end{array}$ & $\begin{array}{c}\mathbf{X}_{3} \\
\text { Loyalitas }\end{array}$ & $\begin{array}{c}\mathbf{Y} \\
\text { Kepuasan konsumen }\end{array}$ \\
\hline 0,482 & 0,646 & 0,806 & 0,857
\end{tabular}

Sumber: Data primer diolah, 2020

44

Saniah et.al (Faktor-faktor yang mempengaruhi kepuasan konsumen kedai "Pesenkopi" di Kota Malang, Brand coffe shop, Consumer loyalti, Costumer's satisfaction, Product quality) 
Validitas deskriminan dilihat dari nilai cross loading dan AVE (Average variances extracted). Oleh karena itu, loading antara 0,40-0,70 harus tetap dipertimbangkan untuk dipertahankan. Selanjutnya dijelaskan pula bahwa indikator dengan loading $<0,40$ dihapus dari model. Penghapusan indikator dengan loading antara 0,40 - 0,70 dilakukan apabila indikator tersebut dapat meningkatkan AVE dan composite reliability diatas nilai batasnya. Nilai batas untuk AVE adalah 0,50 dan nilai batas composite reliability adalah 0,50.

Tabel 5 menunjukkan bahwa ada salah satu variabel yang mempunyai nilai AVE di bawah 0,50 yaitu $X_{1}$ (Kualitas produk), sedangkan $X_{2}$ (merek), $X_{3}$ (loyalitas), dan $Y$ (kepuasan konsumen) sudah memenuhi validitas pada setiap instrumen. Variabel $X_{1}$ memiliki nilai AVE 0,482 $<0,50$ (mendekati 0,50 namun masih valid). Variabel $X_{2}$ memiliki nilai AVE 0,646 $>0,50$ valid. Variabel $X_{3}$ memiliki nilai AVE 0,806 $>0,50$ valid dan nilai $Y 0,857>$ dari 0,50 valid, sudah memenuhi kriteria di atas 0,50 dan dinyatakan bahwa semua variabel valid.

\section{Evaluasi Model Struktural (Inner Model)}

Nilai R-Square memiliki fungsi untuk melihat tingkat kualitas model yang digunakan. Apabila nilai R-Square semakin tinggi, berarti semakin baik pula model penelitian. Model yang kuat, moderat, dan lemah ditunjukkan dengan nilai R-Square berturut-turut sebesar 0,70; 0,50; dan 0,25 (Solimun et al, 2017).

Tabel 6. Hasil nilai R-Square

\begin{tabular}{cl}
\hline \multicolumn{1}{c}{ Variabel } & \multicolumn{1}{c}{ R-square } \\
\hline Y (Kepuasan Konsumen) pertama & 0,731 (R-squared coefficients) \\
Y (Kepuasan Konsumen) kedua & 0,719 (Adjusted R-squared coefficients) \\
\hline
\end{tabular}

Sumber: Data primer diolah, 2020

$Q^{2}=1-\left(1-R_{1}\right)\left(1-R_{2}\right)$

$Q^{2}=1-(1-0.731)(1-0.719)=0,924$

Nilai R-Square pada Tabel 6 menunjukkan bahwa keragaman variabel kualitas produk, merek dan loyalitas sebesar $73,1 \%$. Variabel kualitas produk, merek, loyalitas memiliki kekuatan prediksi yang kuat terhadap kepuasan konsumen. R-square variabel kedua yaitu kepuasan konsumen bernilai 0,719. Hal ini menunjukkan bahwa keragaman variabel kualitas produk, merek, loyalitas mampu menjelaskan variabel keputusan pembelian sebesar $71,9 \%$. Kedua nilai R-square tersebut menunjukkan prediksi yang kuat terhadap kepuasan konsumen.

Hasil perhitungan nilai $\mathrm{Q}^{2}$ untuk model analisis SEM-PLS adalah 0,924 berarti nilai kontribusi variabel kualitas produk, merek dan loyalitas berpengaruh terhadap kepuasan konsumen sebesar $92,4 \%$. Sedangkan sisanya 7,6\% merupakan kontribusi dari variabel lain yang tidak dibahas dalam penelitian ini. Nilai $Q^{2}$ tersebut lebih dari 0,35 maka dapat disimpulkan bahwa predictive relevance dalam penelitian ini adalah kuat.

\section{Hasil Uji Hipotesis}

Hasil model PLS dapat dilihat pada Gambar 1. Pengujian hipotesis dilakukan berdasarkan hubungan kausalitas antara variabel produk, merek, loyalitas konsumen, dan kepuasan konsumen. Hipotesis diterima jika nilai $p<0,05$.

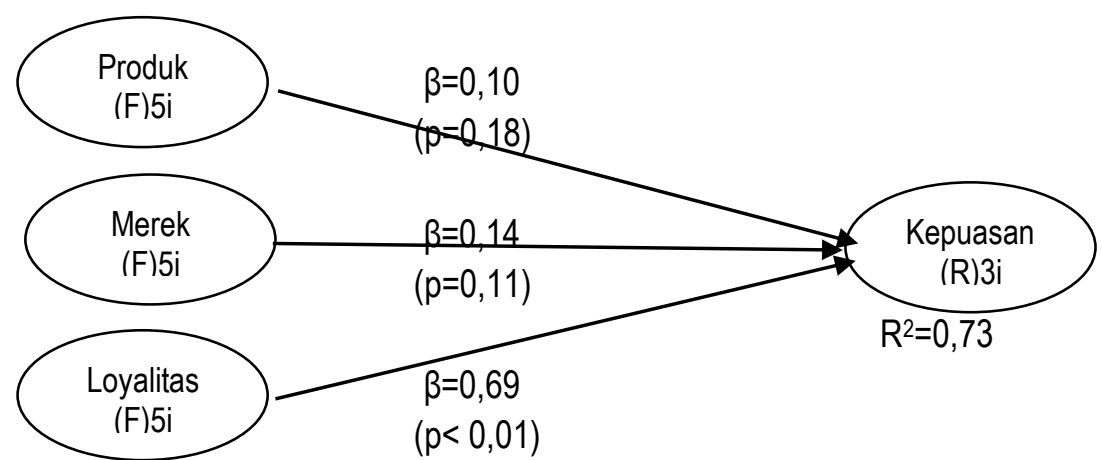

Gambar 1. Hasil model PLS (Partial Least Square)

Saniah et.al (Faktor-faktor yang mempengaruhi kepuasan konsumen kedai "Pesenkopi" di Kota Malang, Brand coffe shop, Consumer loyalti, Costumer's satisfaction, Product quality) 
Pada Gambar 1 dan Tabel 7 dapat dilihat bahwa nilai $P<0,05$ terdapat pada hubungan kausalitas antara Loyalitas terhadap Kepuasan. Berarti hanya ada satu hipotesis yang signifikan dalam model penelitian ini, yaitu hipotesis ketiga.

Tabel 7. Hasil pengujian hipotesis

\begin{tabular}{cccccc}
\hline Hipotesis & Jalur & Koef. jalur & Nilai $\mathbf{P}$ & Ideal & Keterangan \\
\hline $\mathrm{H}_{1}$ & $\mathrm{X}_{1}-\mathrm{Y}$ & 0,103 & 0,179 & $<0,05$ & Tidak Signifikan \\
$\mathrm{H}_{2}$ & $\mathrm{X}_{2}-\mathrm{Y}$ & 0,139 & 0,106 & $<0,05$ & Tidak Signifikan \\
$\mathrm{H}_{3}$ & $\mathrm{X}_{3}-\mathrm{Y}$ & 0,693 & $<0,001$ & $<0,05$ & Signifikan \\
\hline
\end{tabular}

Sumber: Data primer diolah, 2020

\section{Hipotesis 1 (pengaruh kualitas produk terhadap kepuasan konsumen)}

Pada Gambar 1 dan Tabel 7 dapat diketahui bahwa kualitas produk tidak berpengaruh signifikan terhadap kepuasan konsumen, karena memiliki nilai $p=0,179$ atau $17,9 \%$. Tingkat signifikansi yang digunakan untuk pengambilan keputusan hipotesis adalah sebesar $5 \%$. Pada variabel kualitas produk, indikator yang memiliki outer loading terbesar adalah X1.4 (aroma kopi) dengan nilai loading 0,836 (lihat Tabel 3). Berarti aroma kopi yang khas "Pesenkopi" memiliki korelasi yang paling tinggi dengan kualitas produk.

Penelitian ini mendukung Hermawan (2011), Irawan (2013) dan Putro et al (2014) bahwa kualitas produk merupakan totalitas fitur dan karakteristik yang yang mampu memuaskan kebutuhan, yang dinyatakan maupun tidak dinyatakan. Kualitas mencakup pula daya tahan produk, kehandalan, ketepatan, kemudahan operasi dan perbaikan, serta atribut- atribut nilai lainnya. Kualitas produk yang terlihat di kedai "Pesenkopi" sudah memenuhi harapan konsumen, dari aspek penyediaan menu dan kemasan sudah cukup memenuhi, tetapi kualitas produk tidak menjadi kepuasan konsumen secara dominan. Kebanyakan konsumen kedai "Pesenkopi" membandingkan dengan kualitas produk kopi yang lain. Rasa yang enak, biji kopi yang berkualitas, aroma kopi yang khas dan tidak meggunakan bahan pengawet juga menjadi faktor yang dapat mempengaruhi kepuasan konsumen.

Kualitas merupakan suatu kondisi yang dinamis yang berhubungan dengan produk, jasa, manusia, proses, dan lingkungan yang memenuhi atau melebihi harapan. Setelah konsumen membeli produk kopi, mereka akan mengevaluasi kesesuaian produk tersebut dengan yang diharapkan (Putro et al, 2014). Sedangkan performance produk kopi merupakan pencerminan penyajian atau tampilan. Pengukuran performance pada dasamya mengacu pada tingkat karakteristik dasar produk kopi tersebut. Sebuah produk dikatakan memiliki performance yang baik bilamana dapat memenuhi harapan (Irawan, 2013).

Kualitas produk merupakan faktor utama yang menjadi pertimbangan konsumen, sebelum konsumen memutuskan untuk membeli suatu produk, pada dasarnya tujuan dari suatu bisnis adalah untuk menciptakan kepuasan pada konsumen karena kepuasan yang akan membuat konsumen terus kembali dan secara tidak langsung hal itu akan sangat menunjang profit perusahaan (Razak, 2019). Produk memiliki arti penting bagi perusahaan karena tanpa adanya produk, perusahaan tidak akan dapat melakukan apapun dari usahanya. Konsumen akan membeli produk kalau mereka tertarik dan merasa cocok, karena itu produk harus disesuaikan dengan keinginan ataupun kebutuhan pembeli agar pemasaran produk berhasil (Hayati \& Sekartaji, 2015). Jlka performance produk kopi melebihi harapan konsumen maka mereka akan merasa puas, namun sebaliknya jika persepsi tentang performance produk lebih rendah dari harapan maka mereka tidak puas (Chadwick, 2019). Demikian juga, layanan yang excellent menunjukkan manajemen yang baik dari suatu bisnis. Layanan kualitas merupakan bentuk performance dari satu pihak (bisnis) pada pihak lain (konsumen) yang bersifat tangible (Lie et al, 2019).

\section{Hipotesis 2 (pengaruh merek terhadap kepuasan konsumen)}

Merek tidak berpengaruh signifikan terhadap kepuasan konsumen kedai "Pesenkopi" karena memiliki nilai nilai $p$ value 0.106 atau $10,6 \%$ artinya variabel merek tidak berpengaruh secara signifikan terhadap kepuasan konsumen. Indikator variabel merek yang memiliki outer loading terbesar yaitu X2.4 (desain kemasan) dengan nilai 0.885 (lihat Tabel 3). Hal ini berarti indikator pembelian produk secara berulang memiliki korelasi yang paling tinggi sesuai dengan variabel merek. Hasil penelitian ini sejalan dengan Anggraini (2013) bahwa loyalitas konsumen ditunjukkan dengan pembelian ulang produk.

46

Saniah et.al (Faktor-faktor yang mempengaruhi kepuasan konsumen kedai "Pesenkopi" di Kota Malang, Brand coffe shop, Consumer loyalti, Costumer's satisfaction, Product quality) 
Merek "Pesenkopi" Malang sudah memiliki citra di kalangan konsumennya. Hal ini terbukti dengan sudah banyak cabang "Pesenkopi" di beberapa daerah (Jember, Surabaya, Malang, Sidoarjo, Kediri dan Bali). Merek kopi yang lebih ternama juga menjadi pembanding kedai "Pesenkopi". Pesenkopi merupakan merek produk kopi sistem take away yang harganya terjangkau sehingga sesuai dengan segmen pasar pelajar atau mahasiswa. Merek tidak menjadi kepuasan konsumen secara dominan, namun reputasi merek juga menjadi faktor yang dapat mempengaruhi kepuasan konsumen. Kedai "Pesenkopi" menjadi pioner kopi take away yang memudahkan pelanggan untuk membeli kopi yang lebih praktis namun mereka tidak membutuhkan tempat untuk berlama-lama menikmati kopi seperti pada kedai kopi biasa (minum di tempat). Merek yang mudah diingat juga mejadi faktor yang mempengaruhi kepuasan konsumen. Sebuah merek dikatakan khusus jika konsumen merasa yakin bahwa merek-merek tersebut benar-benar khusus (Tombokan, 2015). Loyalitas merek didefinisikan sebagai evaluasi terhadap pengalaman pembelian suatu merek (Chadwick, 2019).

Citra merek adalah apa yang dipersepsikan oleh konsumen mengenai sebuah merek. Perusahaan berkompetisi untuk menguasai pangsa pasar yang ada, yaitu dengan cara membuat perencanaan pemasaran yang baik demi mendapat pencitraan yang positif di benak konsumen. Pihak manajemen perusahaan juga dituntut agar dapat meningkatkan dan mempertahankan pelanggan yang ada (Lasander, 2013). Ekuitas merek adalah nilai tambah yang diberikan pada produk dan jasa. Ekuitas merek berdasarkan perspektif konsumen adalah pengenalan konsumen atas merek tersebut dan menyimpannya dalam memori merek yang mendukung, kuat, dan unik. Ekuitas ini terdiri dari atas kesadaran merek dan citra merek (Wijaya, 2013). Image atau citra adalah realitas, oleh karena itu jika komunikasi pasar tidak cocok dengan realitas, secara normal realitas akan menang. Citra akhirnya akan menjadi baik, ketika konsumen mempunyai pengalaman yang cukup dengan realitas baru (Tamaka, 2013).

\section{Hipotesis 3 (Pengaruh variabel loyalitas terhadap kepuasan konsumen)}

Loyalitas berpengaruh signifikan terhadap kepuasan konsumen karena memiliki nilai $p<0.001$ atau kurang dari $1 \%$ artinya variabel loyalitas berpengaruh secara signifikan terhadap kepuasan konsumen. Nilai path coefficent sebesar 0,693 menunjukkan ada korelasi kuat. Indikator variabel loyalitas yang memiliki outer loading terbesar adalah X3.2 dengan nilai loading 0.924 (lihat Tabel 3). Indikator X3.2 adalah merekomendasikan produk kepada orang lain, memiliki korelasi yang palng tinggi dengan variabel loyalitas konsumen. Hasil penelitian ini mendukung Ishak (2009) bahwa loyalitas berpengaruh terhadap kepuasan konsumen. Hasil ini juga mendukung Romdonny et al (2019) dan Wantara (2019) meskipun dengan arah kausalitas yang berbeda, bahwa semakin tinggi kepuasan konsumen akan semakin tinggi loyalitas konsumen, dan akan semakin tinggi pula keuntungan yang diperoleh perusahaan.

Loyalitas adalah kesetiaan konsumen terhadap suatu barang, ini penting bukan hanya untuk profit tetapi juga kepercayaan konsumen terhadap produk. Loyalitas konsumen kedai "Pesenkopi" Malang ditunjukkan dengan beberapa cara, yakni: memberi informasi kepada orang lain tentang kedai "Pesenkopi", menyukai semua menu produk Pesenkopi, loyal karena tidak ada produk lain yang sesuai dengan keinginan, dan membeli ulang produk "Pesenkopi".

Loyalitas berkaitan dengan apa yang dilakukan konsumen setelah berinteraksi dalam suatu proses layanan. Konsep ini menyiratkan bahwa kepuasan konsumen saja tidaklah cukup, karena puas atau tidak puas hanyalah salah satu bentuk emosi. Sikap loyal konsumen akan timbul setelah konsumen merasakan puas atau tidak puas terhadap layanan yang diterima (Hidayat, 2009). Loyalitas pelanggan merupakan kelanjutan dari kepuasan konsumen, walaupun sebenarnya tidak mutlak merupakan hasil kepuasan konsumen. Dua kondisi penting yang berhubungan dengan loyalitas adalah retensi pelanggan dan total pangsa pelanggan (Kurniawati, 2014). Upaya untuk mempertahankan pasar adalah dengan menciptakan kepuasan konsumen, karena kepuasan konsumen merupakan salah satu kunci keberhasilan suatu usaha. Kepuasan konsumen mempengaruhi perilaku pembelian: konsumen yang puas cenderung menjadi konsumen loyal, tetapi konsumen loyal bukan berarti puas (Pramudyo, 2012).

Konsep loyalitas konsumen lebih menekankan kepada perilaku pembeliannya bersedia mengikatkan diri secara sukarela sehingga mau memiliki komitmen untuk melakukan pembelian ulang suatu produk atau jasa dan/atau merek tertentu secara teratur bahkan merekomendasikan orang lain untuk membeli produk/jasa yang dia beli (Oktasari, 2014). Pengusaha harus bekerja keras untuk mempertahankan loyalitas konsumen karena semakin ketatnya persaingan secara tidak langsung akan mempengaruhi suatu usaha dalam mempertahankan pangsa pasar (Syoalehat, 2016). Kepuasan pelanggan merupakan kunci dalam menciptakan loyalitas pelanggan. Banyak manfaat yang diterima oleh perusahaan dengan tercapainya tingkat kepuasan pelanggan yang tinggi, yakni selain dapat meningkatkan loyalitas pelanggan (Aryani \& Rosinta, 2010).

Saniah et.al (Faktor-faktor yang mempengaruhi kepuasan konsumen kedai "Pesenkopi" di Kota Malang, Brand coffe shop, Consumer loyalti, Costumer's satisfaction, Product quality) 


\section{KESIMPULAN}

Loyalitas konsumen memiliki pengaruh sangat signifikan terhadap kepuasan konsumen kedai "Pesenkopi", sedangkan kualitas produk dan merek berpengaruh tidak signifikan. Indikator loyalitas yang paling penting adalah merekomendasi produk pada orang lain. Meskipun pengaruhnya tidak signifikan, tetap harus diperhatikan bahwa indikator kualitas produk yang paling penting adalah aroma kopi khas "Pesenkopi", dan indikator paling penting dari merek adalah kemasan yang menarik dan praktis.

Rekomendasi praktis yang diberikan adalah aroma kopi khas "Pesenkopi" harus tetap dijaga dan disertai pelayanan yang baik, agar citra merek yang sudah dimiliki mendorong konsumen merekomendasikan produk pada orang lain. Saran untuk penelitian mendatang adalah mengkaji lebih detil tentang intensitas pembelian dan memperdetil karakteristik konsumen remaja untuk segmentasi pasar yang lebih fokus.

\section{DAFTAR PUSTAKA}

Anggraini, A., Pradhanawati, A., \& Nugraha, H. (2013). Pengaruh Kualitas, Citra dan Merek Terhadap Loyalitas dengan Kepuasan Sebagai Variabel Intervening pada Pengguna Layanan Kartu Prabayar IM3 (Studi Pada Mahasiswa FISIP Universitas Diponegoro Semarang). Jurnal IImu Administrasi Bisnis, 1(1), 254-260. Retrieved from https://ejournal3.undip.ac.id/index.php/jiab/article/view/1643

Aryani, Dwi \& Rosinta, F. (2010). Pengaruh Kualitas Layanan Terhadap Kepuasan Pelanggan dalam Membentuk Loyalitas Pelanggan. Bisnis \& Birokrasi: Jurnal IImu Administrasi dan Organisasi, 17(2), 114126. Retrieved from https://scholar.google.com/scholar?hl=en\&as sdt=0\%2C5\&q=Pengaruh+Kualitas+Layanan+Terhadap+Ke puasan+Pelanggan+dalam+Membentuk+Loyalitas+Pelanggan\&btnG=

Chadwick, C. (2019). Product Quality, Convenience and Brand Loyalty: A Case Study of Silverqueen's Adolescent Consumers. International Conference on Business And Management Research, 72 (ICBMR 2018), 111-115.

Irawan, Deny (2013). Analisa Pengaruh Kualitas Produk Terhadap Loyalitas Melalui Kepuasan Sebagai Variabel Intervening Pada Pelanggan Restoran Por Kee Surabaya. Jurnal Strategi Pemasaran, 1(2), 1-8.

Fatlahah, A. (2013). Pengaruh Kualitas Produk dan Citra Merek. IImu Manajemen, 1(2), 472-485.

Gedalia, Catherina. C. (2015). Pengaruh Kualitas Layanan dan Brand Image terhadap Loyalitas Konsumen dengan Kepuasan Konsumen sebagai Variabel Intervening (Studi Kasus Monopole Coffee Lab Surabaya). Jurnal Strategi Pemasaran, 3(1), 1-10. Retrieved from http://publication.petra.ac.id/index.php/manajemenpemasaran/article/view/3351

Harianto, David \& Subagio, H (2013). Analisa Pengaruh Kualitas Layanan, Brand Image, dan Atmosfer terhadap Loyalitas Konsumen dengan Kepuasan Konsumen sebagai Variabel Intervening Konsumen Kedai Deja-Vu Surabaya. Jurnal Strategi Pemasaran, 1(1), 1-8. Retrieved from http://publication.petra.ac.id/index.php/manajemen-pemasaran/article/view/185

Hayati, Y.H., \& Hakim, A.L. (2014). Pengaruh Diskriminasi Harga Terhadap Peningkatan Penjualan Kartu Perdana IM3 Pada PT. Nusapro Telemedia Persada Bogor. JIMFE (Jurnal IImiah Fakultas Ekonomi) 1(2), 58-67.

Hayati, Y.H. \& Sekartaji, G. (2015). Pengaruh Kualitas Produk Terhadap Kepuasan Konsumen Di Restoran Bebek dan Ayam Goreng Pak Ndut Solo. Jurnal IImiah Manajemen Fakultas Ekonomi, 1(1), 49-56.

Hermawan, B. (2011). Pengaruh Kualitas Produk Terhadap Kepuasan, Reputasi Merek dan Loyalitas Konsumen Jamu Tolak Angin PT. Sido Muncul. Jumal Manajemen Teori Dan Terapan (2), 9-17.

Hidayat, R. (2009). Pengaruh Kualitas Layanan, Kualitas Produk dan Nilai Nasabah Terhadap Kepuasan dan Loyalitas Nasabah Bank Mandiri. Manajemen dan Kewirausahaan, 11(1), 59-72.

Ishak, A. (2009). Pengaruh Kepuasan dan Kepercayaan Konsumen Terhadap Loyalitas : Studi Tentang Peran Mediasi. Jurnal Siasat Bisnis, 15(1), 55-66.

Kotler, Philip \& Keller, K.L., 2012. Marketing Management. 14 Ed. Prentice Hall.

Kurniawan, Aditya S. (2011). Pengaruh Trust In A Brand Terhadap Loyalitas Pelanggan (Studi Pada Starbuck Coffee Di Semarang). Skripsi Fakultas Ekonomi Universitas Diponegoro Semarang. Retrieved from

48

Saniah et.al (Faktor-faktor yang mempengaruhi kepuasan konsumen kedai "Pesenkopi" di Kota Malang, Brand coffe shop, Consumer loyalti, Costumer's satisfaction, Product quality) 
http://eprints.undip.ac.id/29536/1/Skripsi012.pdf

Kurniawati, D. (2014). Kepuasan dan Loyalitas Pelanggan (Studi Pada Pelanggan KFC Cabang Kawi Malang). Administrasi Bisnis, 14(2), 1-9.

Kusumasasti, I., Andarwati, A., Hadiwidjojo, D., (2017). Pengaruh Kualitas Produk dan Layanan terhadap Loyalitas Pelanggan Coffee Shop. Ekonomi Bisnis, 22(2), 123-129. Retrieved from http://journal2.um.ac.id/index.php/ekobis/article/view/2364

Lasander, C. (2013). Citra Merek, Kualitas Produk, dan Promosi Pengaruhnya Terhadap Kepuasan Konsumen Pada Makanan Tradisional. Ekonomi Manajemen Bisnis Dan Akuntansi, 1(3), 284-293.

Liany, Feby (2016). Pengaruh Kualitas Produk Minuman Kopi Terhadap Kepuasan Konsumen Di Yellow Truck Coffee Bandung. Skripsi, 1-110. Retrieved from http://repository.stpbandung.ac.id/handle/123456789/197

Lie, D., Sudirman, A., \& Butarbutar, M. (2019). Analysis of Mediation Effect of Consumer Satisfaction on The Effect of Service Quality, Price and Consumer Trust on Consumer Loyalty. International Joumal of Scientific \& Technology Research, 8(08).

Lintong, Debry Chrystie A. (2014). Analisis Pengaruh Kepercayaan, Nilai Pelanggan, Citra Perusahaan terhadap Kepuasan Pelanggan dan Loyalitas Merek (Studi pada Konsumen Minuman Coca-Cola di Manado). Jurnal Manajemen Bisnis dan Inovasi, 1 (2). pp. 115-124. Retrieved from http://repo.unsrat.ac.id/1414/

Lukman, Marco D. (2014). Analisis Pengaruh Ekuitas Merek Terhadap Keputusan Pembelian Dan Kepuasan Konsumen Produk Teh Botol Sosro Kemasan Kotak. Administrasi Bisnis, 10(1), 64-81. Retrieved from http://digilib.mercubuana.ac.id/manager/t!@file_artikel_abstrak/Isi_Abstraksi_472412313276.pdf

Marliana, Rika (2017). Pengaruh Kualitas Pelayanan Terhadap Kepuasan Konsumen Dan Implikasinya Terhadap Loyalitas Konsumen Pada Starbucks Coffee Di Braga City Walk Bandung. ALMANA Jurnal Manajemen dan Bisnis, 1(2), 48-62. Retrieved from http://journalfeb.unla.ac.id/index.php/almana/article/view/360

Oktasari, Y. M. (2014). Peranan Ekuitas Merek Terhadap Loyalitas Pelanggan Handphone Cina di Kota Yogyakarta. Ekonomi dan Bisnis Islam, Viii(2), 156-169.

Pramudyo, A. (2012). Pengaruh Citra Merek Terhadap Loyalitas Melalui Kepuasan Sebagai Intervening (Studi Pada Mahasiswa Perguruan Tinggi Swasta di Yogyakarta). Bisnis Manajemen Akuntansi, I(1), 1-16.

Razak, I. (2019). Pengaruh Kualitas Produk Terhadap Kepuasan Pelanggan. Jurnal Manajemen Bisnis Krisnadwipayana, $7(2)$.

Romdonny, J., Lucky, M., \& Rosmadi, N. (2019). Factors Affecting Customer Loyalty In Products. Budapest International Research And Critics Institute-Journal (BIRCl-Journal), 2(1), 337-343.

Saraswati, P. (2014). Kepuasan dan Loyalitas Pelanggan (Survey Pada Pelanggan Coffee Shop Starbucks di Surabaya dan Kuala Lumpur ). Jurnal Administrasi Bisnis, 14(1), 1-8.

Putro, Shandy W., H.Samuel, R. Karina, Brahmana (2014). Pengaruh Kualitas Layanan Dan Kualitas Produk Terhadap Kepuasan Pelanggan dan Loyalitas Konsumen Restoran Happy Garden Surabaya. Manajemen Pemasaran, 2(1), 1-9.

Solimun, Fernandes, A.A.R., Nurjannah (2017). Metode Statistika Multivariat Pemodelan Persamaan Struktural (SEM) Pendekatan WarpPLS. UB Press.

Syoalehat, Q. N., Azizah, S., \& Kusumastuti, E. (2016). Pengaruh Citra Merek (Brand Image) terhadap Loyalitas Konsumen Bakso Bakar Pak Man Kota Malang. IImu-IImu Peternakan, 26(3), $20-26$.

Tamaka, I. (2013). Citra Merek, Ekuitas Merek, dan Kualitas Produk Pengaruhnya Terhadap Sikap Konsumen Pada Produk Daihatsu Di PT. Astra Internasional Daihatsu Manado. EMBA, 1(3), 1317-1328.

Tombokan, F. (2015). Pengaruh Kualitas Pelayanan, Citra Merek terhadap Kepuasan Konsumen Pengguna Taplus BNI Kantor Cabang Utama Manado The. EMBA, 3(3), 552-561.

Wantara, Q. (2019). The Effect of Price and Product Quality Towards Customer Satisfaction and Customer Loyalty on Madura Batik. International Tourism and Hospitality Jurnal, 2(1), 1-9.

Wijaya, M. H. P. (2013). Promosi, Citra Merek, dan Saluran Distribusi Pengaruhnya terhadap Keputusan Pembelian Jasa Terminix di Kota Manado. EMBA, 1(4), 105-114.

Wijayanto, Indra \& Iriani, S.S. (2013). Pengaruh Citra Merek Terhadap Loyalitas Konsumen. IImu Manajemen, 1(3), 910-918. Retrieved from https://jurnalmahasiswa.unesa.ac.id/index.php/jim/article/view/4557

Saniah et.al (Faktor-faktor yang mempengaruhi kepuasan konsumen kedai "Pesenkopi" di Kota Malang, Brand coffe shop, Consumer loyalti, Costumer's satisfaction, Product quality) 